\title{
A DANÇA COMO COMPONENTE CURRICULAR DA DISCIPLINA DE ARTE NO ENSINO MÉdio INTEGRAdo NO IF SUDESTE MG
}

\author{
DANCE AS A CURRICULAR COMPONENT OF THE DISCIPLINE OF ART IN \\ INTEGRATED HIGH SCHOOL IN THE IF SUDESTE MG
}

\author{
(D) Paulo Cezar da Silva \\ Mestrando em Pós-graduação em Educação Profissional e Tecnológica \\ Instituto Federal Sudeste Campus Rio Pomba (IF Sudeste Rio Pomba) \\ Rio Pomba, MG - Brasil \\ pcdanca@gmail.com \\ Beatris Cristina Possato \\ Doutora pela Universidade Estadual de Campinas (UNICAMP) \\ Instituto Federal Sudeste Campus Santos Dumont (IF Sudeste Santos Dumont) \\ Santos Dumont, MG - Brasil \\ bia.possato@ifsudestemg.edu.br
}

\begin{abstract}
Resumo: Esta pesquisa discute a inserção da Dança como componente curricular obrigatório na disciplina de Arte nos cursos de Ensino Médio Integrado do IF Sudeste MG. Reflete sobre a importância do ensino da Arte e da Dança no ensino integral valorizando a Arte e a Cultura, diante da ausência de professores com formação específica e da abordagem da Dança entre os conteúdos da disciplina de Arte. Optou-se pela pesquisa documental nos projetos pedagógicos dos cursos, nos planos analíticos da disciplina de Arte e demais documentos, que revelaram a disparidade entre a carga horária ofertada para disciplina, em comparação ao Ensino Médio normal dos estados de Minas Gerais, São Paulo e Paraná. A análise bibliográfica sobre o ensino das artes e da dança na educação brasileira revelou os desafios enfrentados ao longo de sua história para sua afirmação, assim como o papel da Arte e da contribuição da Dança como disciplina enquanto área de conhecimento, acerca da produção de saberes para educação do corpo na formação do estudante para o EMI.
\end{abstract}

Palavras-chave: dança; arte; ensino médio integrado; base nacional curricular comum (BNCC); parâmetros curriculares nacionais (PCN).

\begin{abstract}
This research discusses the insertion of dance as a mandatory curricular component in the discipline of Art in Integrated High School courses at the IF Sudeste MG. It reflects on the importance of teaching Art and Dance in integral education, valuing Art and Culture, given the absence of teachers with specific training and the approach to Dance among the contents of the Art discipline. We opted for documental research in the Pedagogical Projects of the Courses, in the Analytical Plans of the discipline of Art and other documents, which revealed the disparity between the hours offered for the discipline, compared to the normal high school in the states of Minas Gerais, São Paulo and Paraná. Bibliographic analysis on the teaching of the arts and dance in Brazilian education revealed the challenges that faced throughout its history for its affirmation, as well as the role of Art and the contribution of dance as a discipline as an area of knowledge, about the production of knowledge for body education in student training for the Integrated High School (IHS).
\end{abstract}

Keywords: dance; art; integrated high school; common national curricular base (CNCB); national curriculum parameters (NCP).

\section{Para citar - ABNT NBR 6023:2018}

SILVA, Paulo Cezar; POSSATO, Beatris Cristina. A dança como componente curricular da disciplina de arte no ensino médio integrado no IF Sudeste MG. Cadernos de Pós-graduação, São Paulo, v. 20, n. 2, p. 115-134, jul./dez. 2021. Disponível em: https://doi.org/10.5585/cpg.v20n2.20162. 
Introdução

No início do século, os PCN - Parâmetros Curriculares Nacionais (BRASIL, 2000) trouxeram à tona a importância da Arte como componente curricular obrigatório no Ensino Médio (EM), como uma área de conhecimento para o desenvolvimento cultural e para a formação artística e estética dos alunos. O documento propôs reflexões e práticas para diferentes linguagens, como a Música, o Teatro, a Dança e as Artes Visuais, considerando sua natureza e a abrangência de suas competências.

Por meio destas, os alunos têm a possibilidade de compreender as manifestações artísticas nas diferentes épocas, bem como suas incontáveis e distintas contribuições à humanidade. O aluno pode refletir de forma estética, crítica e contextual sobre as questões socioculturais do mundo, contextualizando a relevância destas expressões como conhecimento humano sensível-cognitivo. Esta proposta é pautada em conteúdos e competências específicas, que estiveram ausentes e sofreram com o descaso ao longo da história da educação no Brasil, conforme informam os PCN: "nas escolas de Ensino Médio no Brasil, ao longo do século XX, nem sempre a Arte tornou-se conhecida pelos alunos com maior envergadura e dinâmica sociocultural como se apresenta na vida humana” (BRASIL, 2000, p. 46).

O ensino da Arte, por meio das diretrizes propostas pelos PCN (BRASIL, 2000), busca contribuir para o fortalecimento da experiência sensível e inventiva dos alunos, trazendo à tona as relações entre as diferentes linguagens artísticas e abordando a área de Linguagens, Códigos e suas Tecnologias. O ensino de Arte possui competências gerais no que se refere ao conhecimento humano, e é igualmente transfixado pela compreensão da Arte, ao voltar a atenção dos alunos para apreciação e para o fazer artístico/estético. As experiências e competências do Ensino Médio não devem estar desassociadas das questões políticas, sociais, tecnológicas, culturais, intelectuais, estéticas, éticas, dentre outras. $\mathrm{O}$ acesso às múltiplas manifestações artísticas, em todas as fases de desenvolvimento do indivíduo, deve ser considerado essencial e merece ser abordado de forma transformadora e responsável (BRASIL, 2000).

Faz-se necessário tomar como referência o papel da Arte na educação, especificamente a Dança, como eixo para a construção de uma identidade consciente e autônoma nas relações entre educador, educando e ambiente educacional. Essa construção apenas se dará com a práxis da Arte na vida escolar (BRASIL, 2000). As manifestações corporais e artísticas existentes em uma instituição denotam a importância apregoada pelos profissionais da educação e pelos espaços educacionais ao ensino da Arte.

É relevante considerar que muitas vezes essas expressões artísticas são escassas no ambiente escolar, devido à formação acadêmica dos docentes que atuam com a disciplina de Arte não 
contemplar a linguagem da Dança. Infelizmente, esta disciplina tem sido ministrada por professores de áreas distintas, os quais não possuem a formação adequada nas linguagens específicas da Arte, fazendo com que tenham dificuldades para atuar de acordo com as orientações dos PCN para cada segmento do ensino. Faz-se necessário, portanto, trazer os conteúdos especializados em cada linguagem artística, permitindo aos estudantes a apreensão de competências fundamentais para a formação e o desempenho social do cidadão (BRASIL, 2000).

A presença das competências em Dança na proposta curricular dos documentos do PCN e a nova proposta de lei da Base Nacional Curricular Comum (BNCC) ${ }^{1}$ tem sua premissa no art. 210 da Constituição de 1988, através das seguintes políticas públicas: Plano Nacional de Educação, Base Nacional Comum Curricular e o Custo Aluno Qualidade; metas e ações que ficaram no papel por muito tempo.

A necessidade da Base Nacional Comum Curricular como parte de um Plano Nacional de Educação foi proposta por especialistas na Conferência Nacional de Educação - CONAE. Mas foi somente em 2014 que o Plano Nacional de Educação (BRASIL, 2014) saiu do papel, contendo 20 metas que visam melhorar a qualidade da Educação Básica. Em quatro delas temos ênfase na necessidade de construção da BNCC, a serem atendidas até 2024.

Art. 210. Serão fixados conteúdos mínimos para o ensino fundamental, de maneira a assegurar formação básica comum e respeito aos valores culturais e artísticos, nacionais e regionais. $\int 1^{\circ} \mathrm{O}$ ensino religioso, de matrícula facultativa, constituirá disciplina dos horários normais das escolas públicas de ensino fundamental. $\int 2^{\circ} \mathrm{O}$ ensino fundamental regular será ministrado em língua portuguesa, assegurada às comunidades indígenas também a utilização de suas línguas maternas e processos próprios de aprendizagem (BRASIL, 1988, s/p).

Os documentos do PCN (BRASIL, 2000) e da BNCC (BRASIL, 2018) são propostas independentes e que se complementam. O primeiro engloba parâmetros e diretrizes educacionais, enquanto o segundo reúne leis e normativas que regem a Educação Básica. Ambos abordam e ponderam sobre a importância do papel da Arte e da Dança no Ensino Médio de forma distinta. Percebe-se, portanto, a necessidade de um maior número de produções científicas que abordem o diálogo da Arte e da Dança no Ensino Médio Integrado (EMI), segmento de ensino considerado novo.

Considerando a presença das competências em Dança na proposta curricular dos PCN e na BNCC, optou-se por investigar os componentes curriculares da disciplina de Arte, em específico a presença e a abordagem das competências em Dança nos cursos de EMI, ofertados pelo Instituto Federal de Educação, Ciência e Tecnologia do Sudeste de Minas Gerais (IF Sudeste MG). Portanto, foi realizada uma pesquisa em temas similares, disponíveis no acervo de teses e dissertações da 
Coordenação de Aperfeiçoamento de Pessoal de Nível Superior (CAPES). Através de busca utilizando especificamente os termos "Instituto Federal" e "Dança", foram encontradas duas pesquisas de Mestrado Profissional em Educação, realizadas no âmbito do Instituto Federal.

A primeira, do ano de 2013 e de autoria de Graziela Silva Ferreira, é denominada "Educação do Corpo pela Dança na Escola Profissionalizante: o contexto do Instituto Federal de Educação, Ciência e Tecnologia da Bahia - IFBA”. Foi uma análise do ensino da Dança no Instituto Federal da Bahia, comparando amostragens entre os campi de Salvador e de Feira de Santana. Os dados foram obtidos a partir de entrevistas semiestruturadas com dois professores efetivos, sendo um da área de Dança e outro da área de Educação Física, o que permitiu uma investigação descritiva e explicativa, permeada pela aproximação e distanciamento epistemológico existente entre as citadas áreas. A autora teve o intuito de identificar e problematizar a existência de conteúdos da Dança no EMI, avaliando sua influência na formação dos estudantes e trazendo discussões acerca da produção de conhecimento e da educação do corpo pela Dança.

A segunda, intitulada "A Dança no Ensino Médio Integrado: um estudo de caso no Instituto Federal de Educação, Ciência e Tecnologia do Maranhão", é do ano de 2017 e foi escrita por Roselia Lobato. A autora investigou a inserção da Dança como componente curricular obrigatório nos cursos técnicos integrados do IFMA, campus São Luís - Monte Castelo. Foi feito um estudo de caso, através da aplicação de questionários com questões fechadas, abertas e de múltipla alternativa. Assim, foram levantados dados sobre as percepções dos estudantes em relação às contribuições da Dança como disciplina curricular obrigatória nos processos de ensino e aprendizagem no EMI.

Observa-se que, embora haja uma expansão crescente dos Institutos Federais (IFs) nos últimos anos, a Arte e a Dança começaram a ocupar os espaços institucionais de forma recente, sendo, por consequência, temas de algumas pesquisas neste âmbito educacional. Portanto, aos poucos, a Arte começa a ter relevância, de maneira a corroborar, enriquecer e enaltecer todas as linhas de pensamento educacional, uma vez que sua maior incidência irá fortalecer as metodologias, didáticas e instrumentos de ensino em prol da construção de saberes em área específica. A Arte é pedra basilar da sociedade em suas incontáveis expressões e manifestações. Entretanto, ainda assim a encontramos sendo paulatinamente suprimida dos currículos escolares (BRASIL, 2000).

O EMI dos Institutos Federais possui características distintas, tendo em vista a sua origem, a sua constituição e as suas bases, em específico o que caracteriza a proposta de ensino integral e integrado no EM. Dentro desse contexto, a Arte e a Dança tem um papel primordial na formação e no desenvolvimento de crianças e jovens. Ressalta-se a relevância desta pesquisa, visto a importância do contato dos educandos com a práxis em Artes e dentro dela, a Dança, que aborda 
o conhecimento e o trabalho com as várias linguagens, visando à formação artística e estética dos alunos, compreendendo que tais experiências são indissociáveis do processo cognitivo. De acordo com os PCN (BRASIL, 2000):

Conhecer arte no Ensino Médio significa os alunos apropriarem-se de saberes culturais e estéticos inseridos nas práticas de produção e apreciação artísticas, fundamentais para a formação e o desempenho social do cidadão. Na escola de Ensino Médio, continuar a promover o desenvolvimento cultural e estético dos alunos com qualidade, no âmbito da Educação Básica, pode favorecer-lhes o interesse por novas possibilidades de aprendizado, de ações, de trabalho com a arte ao longo da vida (BRASIL, 2000, p. 46).

\section{A disciplina de arte no IF Sudeste MG}

Optou-se por uma abordagem metodológica qualitativa a fim de descrever e alcançar os objetivos desta pesquisa. Os procedimentos técnicos foram a pesquisa bibliográfica e a pesquisa documental (MENEZES et al, 2019). Na pesquisa de revisão bibliográfica, os documentos analisados estão direta e indiretamente relacionados ao Ensino Médio Integrado à Educação Profissional e Tecnológica. Essa metodologia permitiu descrever e compreender a relevância de fatos históricos da Arte como disciplina, dos pressupostos que caracterizam a Educação Profissional e Tecnológica nos Institutos Federais e da importância da Dança para desenvolvimento integral do jovem. Esses saberes se inter-relacionam numa teia de processos dinâmicos cuja complexidade de problemas possibilitou, dentre outros aspectos, investigar, compreender, analisar e refletir sobre a presença das competências em Dança na disciplina de Arte no EMI, conforme as diretrizes dos PCN (2000).

Foi realizada uma análise dos projetos pedagógicos de curso (PPCs), disponíveis no site do IF Sudeste MG, com intuito de verificar quais cursos do EMI possuem a disciplina de Arte no currículo. Foi verificado que os campi de Barbacena, Santos Dumont, Juiz de Fora, Muriaé, Rio Pomba e São João del-Rei, oferecem cursos de Ensino Médio Integrado e todos possuem a disciplina de Arte nos PPCs. São 23 cursos no total. Os campi de Ubá, Manhuaçu, Cataguases e Bom Sucesso, não possuem cursos de EMI. 
Tabela 1 - Número de cursos de ensino médio integrado em cada campus do IF Sudeste/MG
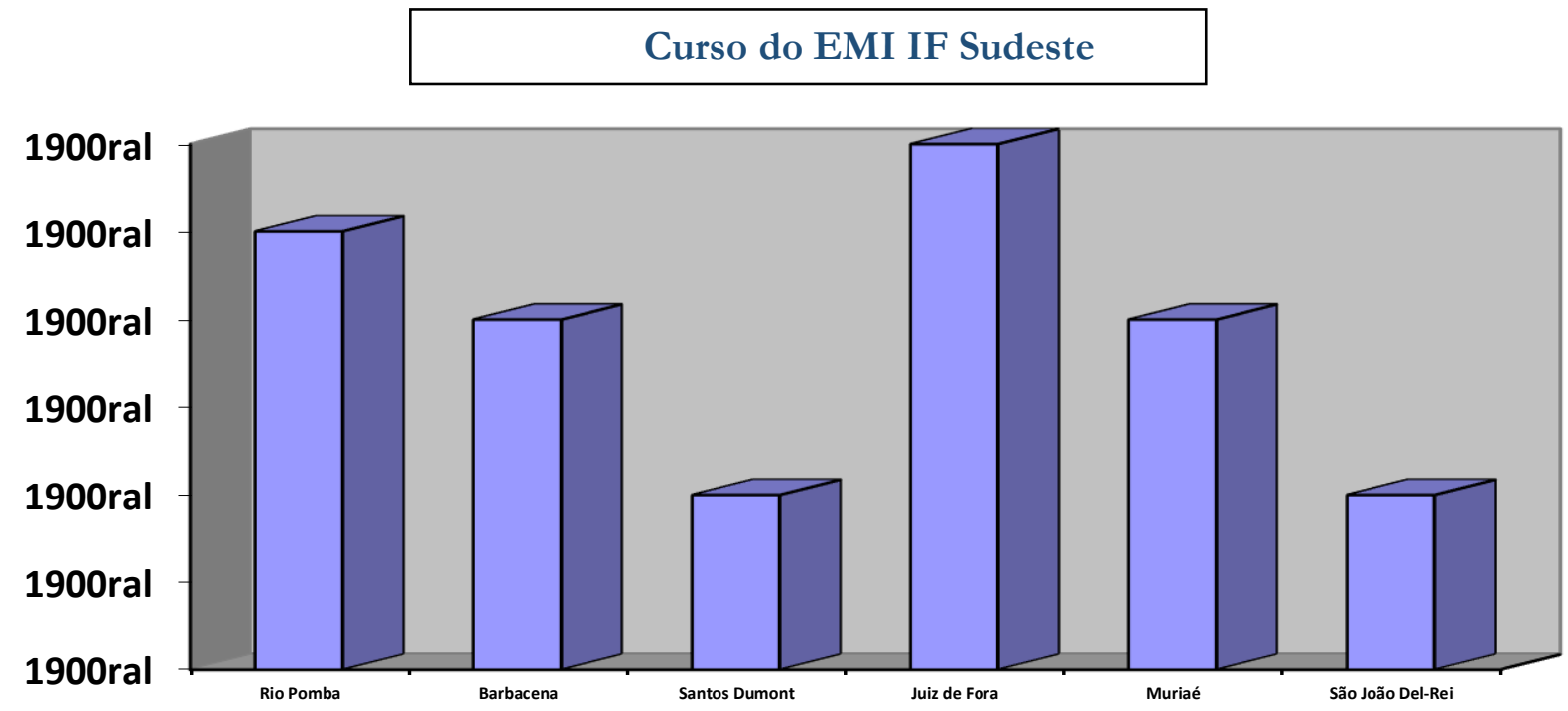

Fonte: Autoria própria.

Constatou-se, por meio da análise dos PPCs dos 23 cursos de EMI, que somente os cursos de Técnico em Edificações e de Técnico em Meio Ambiente do campus São João del-Rei possuem duas aulas da disciplina Arte no decorrer do EM. Os demais cursos possuem a disciplina em apenas um dos anos, variando entre o primeiro e segundo ano do EM. Os campi de Barbacena, Santos Dumont, Juiz de Fora, Muriaé, Rio Pomba e São João del-Rei, que possuem a disciplina de Arte nos currículos dos cursos de EMI, foram selecionados para investigar como as competências de Arte, em específico de Dança, estão presentes dentro do programa analítico das disciplinas ofertadas.

Foi feito também um comparativo da quantidade e tempo de horas das aulas na disciplina de Arte nos três anos do Ensino Médio em três estados distintos: Minas Gerais, São Paulo e Paraná. Após a coleta de dados, estes foram correlacionados com as mesmas informações pertinentes a maioria dos campi do IF Sudeste MG. 
Tabela 2 - Número de horas aulas anual no ensino médio Integrado IF/Sudeste em comparação com EM nos estados de Minas Gerais, São Paulo e Paraná.

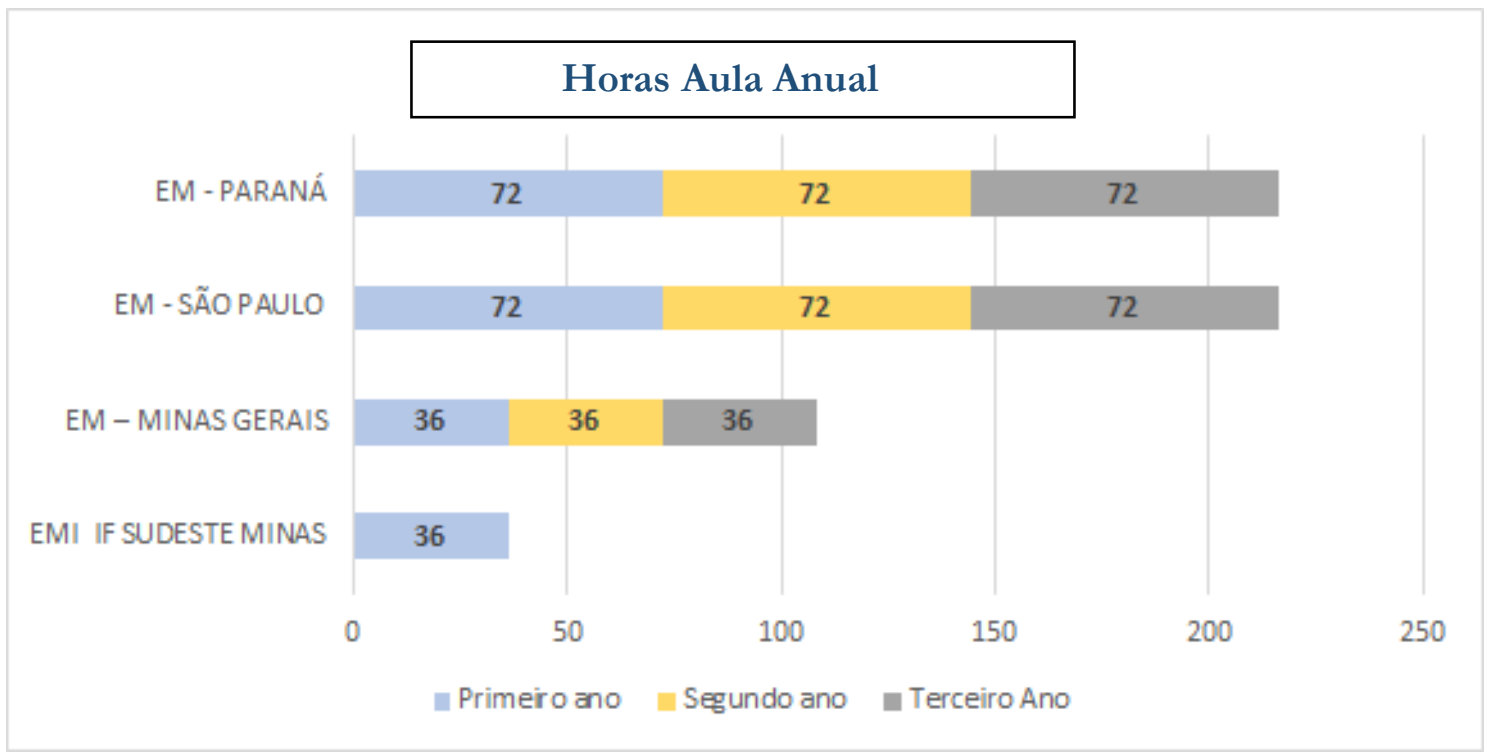

Fonte: Autoria própria.

A quantidade de horas/aulas na disciplina de Arte do IF Sudeste MG é bastante inferior se comparada a dos estados de Minas Gerais, São Paulo e Paraná. Enquanto os estados Paraná e São Paulo ministram duas aulas da disciplina de Arte por semana em cada ano, Minas Gerais ministra apenas uma em cada ano. Comparando os cursos de EMI do IF Sudeste MG com as turmas de EM da rede estadual de ensino de Minas Gerais, observa-se, conforme gráfico acima, uma diferença de 36 horas no EMI do IF Sudeste MG em comparação às 108 horas no Ensino Médio da referida rede, ao longo dos três anos do Ensino Médio.

A diferença fica maior e mais evidente quando comparamos as turmas do EMI do IF Sudeste MG, com as turmas do EM de São Paulo e Paraná, uma vez que nestes estados, os alunos têm o total de duzentas e dezesseis horas ao longo dos três anos do EM. As turmas do EMI do IF Sudeste MG possuem, em sua formação, o total de trinta e seis horas de aulas de Artes ao longo dos três anos de EMI, com exceção das turmas de São João del-Rei que possuem setenta e duas horas. Já as turmas de EM do estado de Minas Gerais tem cento e oito horas de aulas de Arte em sua formação. O quadro comparativo abaixo apresenta as horas-aula de Arte no total dos três anos do Ensino Médio no IF Sudeste MG e nos estados de Minas Gerais, São Paulo e Paraná. 
Tabela 3 - Comparativo entre número de aulas entre EMI do IF Sudeste/MG e o EM dos estados de Minas Gerais, São Paulo e Paraná.

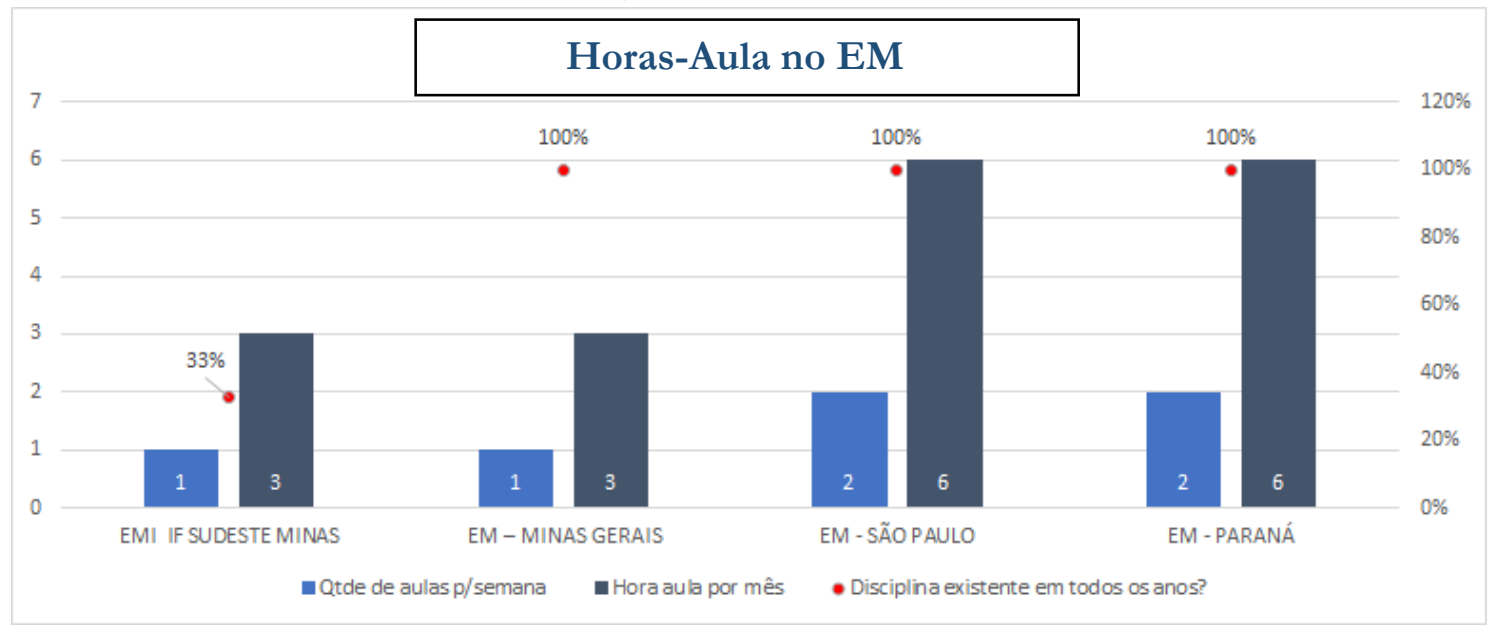

Fonte: Autoria própria.

Conforme os PCN (2000), a articulação entre Ensino Médio e Educação Profissional não se dá por sobreposição. Os estudos de formação geral e de preparação básica para o trabalho, tidos como essenciais à habilitação profissional, podem ser inclusos na carga horária mínima de duas mil e quatrocentas horas prevista para o Ensino Médio. Do mesmo modo, podem ser aproveitados $25 \%$ da formação básica na carga horária exigida para a formação profissional.

\footnotetext{
Quando o mesmo Decreto 2.208/97 afirma em seu Artigo 2o: A educação profissional será desenvolvida em articulação com o ensino regular [...], e depois, no já citado Artigo 5o, reafirma que: A educação profissional terá organização curricular própria e independente do ensino médio, podendo ser oferecida de forma concomitante ou sequencial a este, estabelece as regras da articulação, sem que nenhuma das duas modalidades de Educação, a Básica, do Ensino Médio, e a Profissional de nível técnico, abram mão da especificidade de suas finalidades (BRASIL, 2000, p. 87).
}

A duração da formação geral, incluída a preparação básica para o trabalho, é inegociável. Já a duração da formação profissional específica será variável, o que afetará a quantidade de tempo a ser alocado à formação geral, pois depende da relação proximal dos saberes presentes na formação básica e como estes podem colaborar para a formação técnica profissional. Quanto maior a proximidade, mais os estudos de formação geral poderão propiciar a aprendizagem de conhecimentos e competências, que são essenciais para o exercício profissional. Portanto, esses estudos podem ser aproveitados na obtenção da habilitação profissional desenvolvidos concomitante ou sequencialmente ao Ensino Médio (BRASIL, 2000).

Sobre a prioridade da formação e dos estudos de preparação básicos aqui apresentados, surge a dúvida se as disparidades encontradas entre a oferta da disciplina de Arte, em específico da 
carga horaria entre EM e EMI, não acarretariam em prejuízo, tomado como retrocesso, afetando assim o ensino das Artes e o educando. A legislação mostra que nos anos mais conservadores da sociedade brasileira, o ensino de Artes foi desconsiderado, menosprezado e subjugado a segundo plano.

Os PCN propõem que "O ensino da arte constituirá componente curricular obrigatório, nos diversos níveis da educação básica, de forma a promover o desenvolvimento cultural dos alunos” (BRASIL, 2000, p.31). Isso é reflexo de propostas neoliberais que acreditam no ensino tecnicista para as massas e que somente as disciplinas diretamente ligadas ao desenvolvimento econômico tem valor.

Estes tensionamentos se delineiam, invariavelmente, pela disputa em torno currículo, ou seja, daquilo que é escolhido para ser ensinado. Este é um dos principais motivos pelo qual a maioria das políticas e programas educacionais preconizam as transformações na Educação a partir de mudanças curriculares, as quais nem sempre se consolidam tendo em vista as fragilidades estruturais, humanas, organizativas e didático-pedagógicas presentes na realidade escolar (JAKIMIU, 2017, p. 6719).

Não iremos nos aprofundar sobre os motivos destas distinções ou realizar investigações referentes à origem das variações de carga horária da disciplina de Arte nos PPCs do IF Sudeste MG. Tampouco iremos verificar o possível impacto destas distinções na proposição de ensino dos IFs. Mas a carga horária reduzida da disciplina de Artes nos permite analisar que, infelizmente, essa disciplina não possui nas instituições citadas o mesmo valor hierárquico das demais disciplinas como Língua Portuguesa, Matemática, entre outras.

Portanto, o intuito dessa pesquisa é analisar se as competências da Dança, propostas pelos PCN (2000), estão presentes no ambiente escolar do EMI do IF Sudeste MG. Ressaltamos tal relevância, visto a importância do contato dos educandos com a práxis em Artes, em específico a Dança, que aborda o conhecimento e o trabalho com as várias linguagens, visando à formação artística e estética dos alunos, compreendendo que tais experiências são indissociáveis do processo cognitivo.

\footnotetext{
Conhecer arte no Ensino Médio significa os alunos apropriarem-se de saberes culturais e estéticos inseridos nas práticas de produção e apreciação artísticas, fundamentais para a formação e o desempenho social do cidadão. Na escola de Ensino Médio, continuar a promover o desenvolvimento cultural e estético dos alunos com qualidade [...] (BRASIL, 2000, p. 46).
}

Os processos de criação e apreensão de saberes em Arte viabilizam experiências de transformação permanentes, resultantes das práticas de produção e apreciação artísticas, que são fundamentais para a formação e o desempenho social do indivíduo. Os conteúdos de Arte para o 
EM devem ampliar a compreensão dos códigos sociais, culturais, intelectuais, além das relações deste com o eu e com o outro (BRASIL, 2000, p. 49).

O pensamento de que as Artes em geral transformam o homem é um consenso científico e social na atualidade. Segundo Wosien (2000), o papel exercido pela Dança é de auxiliar o indivíduo na construção de uma identidade por intermédio das sensações, emoções e sentimentos experienciados, através de estímulos específicos e da interação com o meio e com o outro. Esta experiência torna-se a base da construção da personalidade, que parte da corporeidade e permite ao educando explorar sua criatividade para conduzir suas emoções e desenvolver uma consciente e saudável liberdade para sua imaginação.

Para Marques (2003) e Barros (2005), todas as relações do homem com o meio são permeadas pelo corpo, sendo por meio deste que se efetiva a construção da identidade e da personalidade. Tais relações atuam sobre a memória corporal, bem como em sua expressão, possibilitando ao educando no EM, fortalecer e construir sua tomada de decisões através dos conteúdos da Dança, formando uma consciência autônoma para expressar opiniões e atitudes por intermédio do trabalho continuado do corpo, como nos coloca a autora:

\footnotetext{
No que diz respeito ao movimento em si, essencial para que a dança se realize, [...] que é por meio da percepção, da experimentação e da análise em nossos corpos do quê, onde, de como e com quem o movimento acontece que podemos também criar, transformar e compreender a dança. [...], pois estamos criando relações simbólicas e significativas entre aquele que interpreta o movimento e o meio (MARQUES, 2003, p. 29).
}

Assim, a Dança, por meio dos processos educativos, deve possibilitar o desenvolvimento essencial da criação e da percepção estética, mobilizando a expressão e a comunicação pessoal do educando, com enfoque na formação do cidadão. As ações devem ser intensificadas nas relações dos indivíduos, no ato de fazer fazendo, conhecendo e vivenciando no corpo sua própria história.

\section{2 - Ensino da arte na escola - itinerários da legislação brasileira}

Várias são as lutas que a disciplina de Arte enfrentou ao longo das últimas décadas para que conteúdos e competências fossem incluídos no currículo do Ensino Básico. Em 1961, a Lei de Diretrizes e Bases da Educação (LDB) n $n^{\circ}$ 4.024, propôs a organização dos diferentes níveis de educação, onde se observavam algumas brechas para o ensino de Artes. Em seu art. 38, capítulo I, consta que "na organização do ensino de grau médio serão observadas as seguintes normas: IV atividades complementares de iniciação artística” (BRASIL, 1961, s/p).

Segundo Vasques (2011), a LDB de 1961 permitia que as instituições de ensino, em todos os níveis, pudessem escolher algumas disciplinas de acordo com o formato dos cursos e/ou 
características regionais. Embora já houvesse o ensino de alguma atividade artística, ainda que fossem as artes aplicadas e (ou) os trabalhos manuais, somente em 1971 o ensino de Arte se tornou obrigatório e regulamentado por lei específica.

Em seguida, no contexto autoritário da Ditadura Militar, foi aprovada a LDB $\mathrm{n}^{\circ}$ 5.692/1971, em que vemos surgir a palavra Arte pela primeira vez na legislação escolar. Ao longo da história de ensino e aprendizagem da Arte, é nítido "certo descaso de muitos educadores e organizadores escolares, principalmente no que se refere à compreensão da Arte como um conhecimento humano sensível-cognitivo" (BRASIL, 2000, p. 47).

(Art. $7^{\circ}$.) Será obrigatória a inclusão de Educação Moral e Cívica, Educação Física, Educação Artística e Programas de Saúde nos currículos plenos dos estabelecimentos de $1^{\circ}$. E $2^{\circ}$. Graus, observando quanto a primeira o disposto no Decreto n.369, de 12 de setembro de 1969 (BRASIL, 1971, s/p).

Tem-se, ao longo da história do Brasil, um quadro de diferentes perspectivas formativas em constante disputa. Antecede a LDB de 1971, o descaso e a fragilidade, e com sua aprovação, concretiza-se a reforma do ensino de $1^{\circ}$ e $2^{\circ}$ graus no Brasil, na qual a Arte é tratada como experiência de sensibilização, através de atividades desconectadas do projeto escolar, abordadas de forma genérica. Sem exigência especializada de formação, permitia-se a polivalência nas áreas: Artes Plásticas, Educação Musical e Artes Cênicas.

\footnotetext{
Somente dois anos depois da implementação da lei 5.692/71 é que o Governo Federal começa a criar primeiros Cursos de Arte-Educação em nível superior [...] constituídos por um currículo básico para ser aplicado em todo o país e foram marcados por um processo de aligeiramento, formando os primeiros professores em apenas dois anos (JAKIMIU, 2017, p. 6723).
}

Segundo Jakimiu (2017), dois anos após a lei de 1971, o governo inicia a criação dos cursos de Arte-Educação em nível superior. Foram criados 78 cursos em Educação Artística, com duração de apenas dois anos para a conclusão. Desde o início do século XX, temos as Artes Visuais (antes Arte Plásticas) presentes em alguns cursos de História da Arte, em escolas normais ou de $2^{\circ}$ graumagistério, onde os conhecimentos propostos se limitavam aos desenhos técnico e geométrico, de caráter descritivo e pedagógico.

De forma reducionista, a história da disciplina de Arte tem início com o florescer das questões sobre seu papel na educação, no ano de 1961. Os debates permitiram que em 1971 houvesse a inclusão da Arte como conteúdo obrigatório no ensino. Somente em 1996 houve sua 
promulgação como disciplina, inicialmente considerada uma atividade educativa, que mesmo obrigatória, não exigia notas.

Segundo Jamikiu (2017), em 1982, através da organização de professores licenciados e de artistas das diversas linguagens, houve o surgimento das Associações de Arte-Educadores em alguns estados. Neste mesmo período emergiram novos estudos sobre o ensino e aprendizagem de Arte, que endossaram mudanças e novos posicionamentos.

Foi um período de enfrentamento da ausência da Arte e das distorções que dificultavam o ensino, impulsionando novas proposições em diferentes frentes, com o apoio de artistas, pesquisadores e educadores. Foram realizados congressos, eventos nacionais e internacionais, organizados por universidades e pela Federação Nacional dos Arte-Educadores do Brasil - FAEB. Esse movimento permitiu trazer à tona questões sobre a necessidade da criação de cursos de Arte, que atendessem às demandas das diversas linguagens artísticas, de professores da pré-escola à universidade, incluindo a necessária formação especializada de profissionais em Arte (JAKIMIU, 2017).

Segundo Jakimiu (2017), a Arte, como currículo, foi abordada inicialmente como atividade complementar, depois como conteúdo extracurricular. A LDB no 9.394/1996 traz em seu art. 26, parágrafo segundo, que “O ensino da arte constituirá componente curricular obrigatório, nos diversos níveis da educação básica, de forma a promover o desenvolvimento cultural dos alunos" (BRASIL, 1996, s/p). Isso resulta da conquista dos Arte-Educadores do Brasil, onde a Arte obteve maior espaço e se tornou componente curricular obrigatório da Educação Básica, com intuito de promover o desenvolvimento cultural.

No ano de 1998, houve a retirada do caráter da polivalência para ensino da Arte, o que permitiu que as linguagens da Música, do Teatro, das Artes visuais e da Dança passassem a ser vistas como autônomas. Isso impulsionou o crescimento de cursos de licenciatura com habilitação específica e trouxe alterações curriculares na graduação em Educação Artística (RODRIGUES, 2013).

Em 2000, foram estruturados os PCN, com a proposta de difundir a reforma curricular e orientar os professores diante da abordagem e da metodologia propostas. No ano de 2008 , houve a alteração da LDB de 1996, através da Lei no 11.769, propondo a Música como conteúdo obrigatório, mas não exclusivo, permitindo a cada instituição decidir a melhor opção, com prazo de três anos para adequação dos sistemas de ensino. A respeito da obrigatoriedade da linguagem da Música no currículo escolar (não exclusiva), a lei foi interpretada como injusta, por priorizar uma linguagem específica em prejuízo das demais que não foram nem mencionadas no texto. 
Em um primeiro momento, a Lei $\mathrm{n}^{\circ} 11.769$ alterava a LDB de 1996, definindo que seria necessário uma formação específica para o ensino da Música. Houve veto do mesmo, questionando o significado de uma formação específia na área, visto que há uma diversidade de profissionais da música sem formação acadêmica. "Vale ressaltar que a música é uma prática social e que no Brasil existem diversos profissionais atuantes nessa área sem formação acadêmica [...]” (BRASIL, 1996, s/p). A justificativa do veto pelo congresso foi à ausência da exigência de formação mínima para ministrar conteúdos específicos relacionados a culturas, etnias e língua estrangeira, segundo a LDB.

No ano de 2010, a LDB de 1996 foi modificada pela Lei n 12.287 , definindo que o ensino de Arte deve considerar as especificidades regionais e locais no processo educativo. Assim, o "ensino da arte, especialmente em suas expressões regionais, constituirá componente curricular obrigatório nos diversos níveis da educação básica, de forma a promover o desenvolvimento cultural dos alunos" (BRASIL, 2010, s/p). Em 2013, houve o lançamento das novas Diretrizes Curriculares para a Educação Básica (DCNEB) e os PCN deixaram de ser referência, passando a ser pressupostos epistemológicos, filosóficos e pedagógicos para formação do educando. Segundo Jamikiu (2017), tais diretrizes tinham o objetivo de tornar sem efeito documentos anteriores como as DCN (BRASIL, 1998) e os PCN (BRASIL, 2000), inclusive da perspectiva da formação,

[...] há um entendimento de que tanto as diretrizes curriculares, quanto os Parâmetros Curriculares Nacionais (PCN), implementados pelo MEC de 1997 a 2002, transformaram-se em meros papéis. Preencheram uma lacuna de modo equivocado e pouco dialógico, [...] Os PCNs teriam sido editados como obrigação de conteúdos a serem contemplados no Brasil inteiro, como se fossem um roteiro (BRASIL, 2013, p. 14).

Mesmo com as críticas às DCNEM (Diretrizes Curriculares Nacionais do Ensino Médio) de 2013, os PCNs permaneceram sendo utilizados como referência educacional na última década, tanto por instituições de ensino, quanto para formação dos profissionais em educação. Jakimiu (2017) tece críticas à proposição da Arte dos PCN, que não possui:

[...] nenhuma densidade teórica, ou seja, uma 'colcha de retalhos', que não tem credibilidade para ser citado e/ou utilizado como base teórica”, com ausência de referências teóricas e citações, assim como, a apropriação da produção teórica de autores relevantes, como Paulo Freire e Ana Mae Barbosa (JAKIMIU, 2017, p. 6724).

Em maio de 2016, a Lei 13.278 alterou a LDB de 1996, determinando o prazo de cinco anos para os sistemas de ensino incluírem as Artes visuais (antes Artes Plásticas), a Dança, a Música e o Teatro como componentes curriculares. Foi dado o prazo de cinco anos para adequação e 
inclusão necessárias, considerando o número insuficiente de professores com formação adequada para atuar.

Jakimiu (2017) aborda os embates gerados pela Lei $\mathrm{n}^{\circ}$ 13.278, de 2016, que incluía a necessidades de quatro profissionais formados em áreas distintas (Dança, Teatro, Artes Visuais e Música), atuando e ocupando o mesmo espaço nas instituições de ensino. Passaram-se os cinco anos desde a referida lei e não houve tempo hábil para incluir as linguagens artísticas no currículo, muito menos oportunizar concursos e processos seletivos específicos. Antes mesmo do prazo de cinco anos, em 2018, surgiu a proposição de reestruturação do Ensino Médio com a BNCC.

A BNCC para a Educação Infantil e para o Ensino Fundamental foi aprovada e homologada em 2017. Um ano depois, em dezembro de 2018, foi disponibilizada a BNCC específica para Ensino Médio. O documento define as aprendizagens essenciais para a educação brasileira a serem desenvolvidas em toda Educação Básica. No mesmo ano, a Lei no 13.415/2017 alterou o conteúdo da LDB de 1996, tornando o "ensino da arte, especialmente em suas expressões regionais, [...] componente curricular obrigatório da educação básica” (BRASIL, 2017, s/p). Aparentemente, a BNCC redefine o papel da Arte (seus conteúdos e competências) para a Educação Básica. Segundo a Federação de Arte-Educadores do Brasil, a BNCC possui uma abordagem vaga da Arte como componente do currículo.

\footnotetext{
Alguns especialistas que atuavam na elaboração da BNCC, do Componente Arte, pediram desligamento e retirada de seus nomes da última versão do documento, pois esses profissionais se sentiram usados apenas para legitimar o processo. Eles não tiveram espaço para cumprir as suas funções de representar a sua comunidade disciplinar e, muito menos, tiveram a oportunidade de fazer valer os principais anseios e exigências da categoria, sendo negligenciadas as diversas vozes de educadores (PERES, 2017, p. 09).
}

Houve discordância dentro dos segmentos de educação, onde a Arte reassume papel coadjuvante no ensino como mera atividade educativa (ou decorativa), como nos anos 70 . Retrocesso no qual, a disciplina pode assumir a função de conteúdo complementar, ministrada por profissionais sem formação específica ou mesmo ser utilizada como recurso didático para o ensino de outras áreas, sem ser mencionada ou estar incluída no currículo, como ao longo dos anos 80 e 90.

Para Barbosa (2017), o processo de construção da BNCC não incluiu os profissionais ArteEducadores e foi calcada na exclusão da classe que vivencia a Arte-Educação nas escolas. A aplicação da nova proposta pode induzir a abstenção e mesmo a exclusão de direitos conquistados anteriormente. Já segundo Jakimiu (2017), as novas bases curriculares foram pensadas por teóricos em Arte-Educação e não a partir e com os Arte-Educadores ou com os professores que atuam na 
área. A autora enfatiza que a pesquisadora Ana Mae Barbosa tomou frente da luta pela educação na área da Arte neste período.

A autora, inclusive, está à frente da Campanha "Todos pela Arte Educação", uma vez que entende que o processo de construção da BNCC não esteja incluindo os Arte-Educadores para pensar uma proposta formativa em Arte, pelo contrário, a BNCC está reproduzindo um processo de exclusão daqueles que realmente fazem Arte-Educação no dia a dia das escolas, [...] (JAKIMIU, 2017, p. 6728).

Segundo Ortega (2019), a Arte no Ensino Médio, ainda se apresenta como 'adorno', no qual conteúdos e proposições nas diferentes linguagens (Dança, Teatro, Música e Artes Visuais) são redundantes ou 'meras' repetições dos conteúdos textuais e metodológicos propostos no Ensino Fundamental I e II. É desconsiderada, toda a grandeza de possibilidades e não há clareza dos conteúdos abordados, trazendo à tona as seis dimensões do conhecimento: criação, crítica, expressão, estesia, fruição e reflexão.

Permanecer com as antigas práticas e hábitos comuns exige menor esforço perante a inclusão do novos referenciais normativos e novas exigências de aprimoramento pedagógico. Como o problema desta pesquisa visa investigar a presença das competências em Dança no EMI, foi salutar fazer uma contextualização histórica, dos caminhos percorridos pela disciplina de Arte, para compreender a inclusão da Dança no currículo. Isso porque as leis, diretrizes e parâmetros são de grande importância na investigação dos documentos institucionais e na compreensão da presença da Arte, em específico da Dança, para formação dos educandos do EMI no IF Sudeste MG.

\subsection{Competências em arte nos PCN}

A disciplina de Arte e seus componentes foram incluídos na parte II dos PCN, destinada a "Linguagens, códigos e suas Tecnologias", com enfoque nos conhecimentos básicos, na preparação científica e no uso de diferentes tecnologias para formação do educando. Para a etapa final de uma educação de caráter geral, era necessária uma disciplina afinada com a contemporaneidade (BRASIL, 2000).

$\mathrm{Na}$ parte I, temos as bases legais que orientam os parâmetros e na parte III, as Ciências da Natureza, Matemática e suas tecnologias. Encontramos na parte IV, as Ciências Humanas e suas tecnologias. Assim, propõe-se que, ao final do EM, o educando seja capaz de pesquisar, buscar informações, analisá-las e selecioná-las, e assim, desenvolver a capacidade de aprender, criar e formular, no lugar do simples exercício de memorização (BRASIL, 2000).

$\mathrm{Na}$ área de Linguagens e Códigos, há destaque para as competências relacionadas a aquisição de saberes, formação da identidade e exercício da cidadania. Nesta área, agrupam-se as 
disciplinas, atividades e conteúdos relacionados às diferentes formas de expressão, estabelece correspondência entre as formas de comunicação e expressão, evidenciando a importância das linguagens "constituintes dos conhecimentos e das identidades dos alunos, de modo a contemplar as possibilidades artísticas, lúdicas e motoras de conhecer o mundo" (BRASIL, 2000, p. 92).

Os PCN do EM têm como objetivo principal que as competências básicas permitam ao educando se situar como sujeito produtor de conhecimento e participante do mundo do trabalho. O currículo deve contemplar as três áreas do conhecimento, com intuito de que as metodologias evidenciem interdisciplinaridade e a contextualização, assegurando o mesmo tratamento às disciplinas de Educação Física e Arte, como componentes curriculares obrigatórios. No segmento da disciplina de Arte, os PCN propõem a reflexão e a troca de ideias, que favoreça os educandos a apropriarem-se de saberes culturais e estéticos inseridos nas práticas de produção e apreciação artísticas, incluindo as práticas artísticas e sua contextualização regional, nacional e internacional (BRASIL, 2000).

A ênfase da educação, segundo os PCN (2000), é subidivida em três bases: econômica, científica e cultural, que visa à integração do homem no universo das relações da política, do trabalho e da simbolização subjetiva, visando assegurar uma educação inclusiva e equitativa proposta através dos eixos estruturais: aprender a conhecer, aprender a fazer, aprender a viver e aprender a ser. Mediante a práxis de Arte, as instituições de ensino e sua equipe multidisciplinar podem auxiliar o indivíduo a ampliar a compreensão dos códigos sociais, sendo essencial a Arte e as suas linguagens específicas para facilitar os processos de apreensão de saberes tomando as experiências estéticas como extensão do existir do homem (BRASIL, 2000).

Marques (2003) e Fernandez (1991) enfatizam que, no desenvolvimento do adolescente, a inserção da Arte deve ocorrer através de processos flexíveis e adaptáveis a cada realidade e indivíduo, possibilitando o entendimento da necessidade de processos diversificados e compatíveis à ação educacional. Propicia um relevante diálogo entre educadores e educandos, onde é fundamental o papel da instituição de ensino e de sua equipe multidisciplinar em auxiliar nos processos de expressão corporal e apreensão de saberes. (BRASIL, 2000).

O educador, por meio da Arte, deve desenvolver diferentes recursos e metodologias para auxiliar na percepção, na imaginação e na investigação reflexiva e sensível do conjunto de práticas do conhecimento humano. Tal apreensão de saberes e autonomia pode ser atingida mediante o contato crítico do aluno com as produções artísticas que o sensibilizam, propiciando que este enverede de forma autônoma por outras experiências criativas individuais e coletivas. As linguagens artísticas possuem um papel fulcral, que deve ser permeado por educadores especializados, para 
que os educandos possam identificar e compreender a Arte em sua relevância histórico-políticosocial (SILVA, 2017).

\section{Breves Reflexões}

Como o problema desta pesquisa visou investigar a presença das competências em Dança no EMI, foi salutar fazer uma contextualização histórica dos caminhos percorridos pela disciplina de Arte, para compreender a inclusão da Dança no currículo. Mas é relevante aprofundar as orientações específicas dos PCN para a disciplina de Arte que norteiam o EM e viabilizar uma

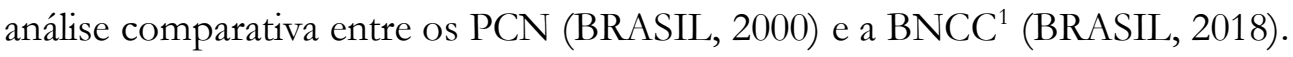

Isso porque as leis, diretrizes e parâmetros são de grande importância na investigação dos documentos institucionais e na compreensão da presença da Arte, em específico da Dança, para formação dos educandos do EMI no IF Sudeste MG. O que se deseja é a autonomia coerente, sem censura e sem exclusão social para o ensino da Arte, independente das circunstâncias e prerrogativas políticas e sociais enfrentadas. Isso permite que o educando distinga e reflita sobre os diferentes códigos e padrões artísticos que caracterizam cada comunidade, possibilitando um olhar singular sob sua realidade, o que possibilita selecionar e construir suas próprias releituras e manifestações artísticas (SILVA; ALEXANDRE, 2014).

[...] as práticas artísticas e estéticas em música, artes visuais, dança, teatro, artes audiovisuais, além de possibilitarem articulações com as demais linguagens da área Linguagens, Códigos e suas Tecnologias, podem favorecer a formação da identidade e de uma nova cidadania do jovem que se educa na escola de Ensino Médio, fecundando uma consciência de uma sociedade multicultural, onde ele confronte seus valores, crenças e competências culturais no mundo no qual está inserido (BRASIL, 2000, p. 50).

Reforça-se a ideia de que a apreensão de saberes da estrutura dos PCN (BRASIL, 2000) depende da formação qualificada e especializada do professor, haja vista a importância do papel deste como intermediador dos constructos viabilizados pelas linguagens artísticas. O educador cria pontes para que os educandos possam desenvolver discernimento na compreensão das diferentes funções da Arte ao longo do ensino.

\footnotetext{
Embora já tenha ocorrido aprovação da nova BNCC (Base Nacional Curricular Comum), em 05 de Dezembro de 2018 , o período para a transição envolve distintas frentes de ação dos estados e municípios, dependendo da formação dos professores e adequação materiais didáticos para ser efetivada. O Ministério da Educação (MEC) prevê duração de dois anos para transição.
} 


\section{Referências}

BARBOSA, A. M. O dilema das Artes no Ensino Médio no Brasil. PÓS: Revista do Programa de Pósgraduação em Artes da EBA/UFMG, v. 7, n. 13, mai. 2017.

BARROS, D. D. Imagem corporal: a descoberta de si mesmo. História, Ciências, Saúde-Manguinhos, v. 12, p. 547-554, 2005. Disponível em:

https://www.scielo.br/j/hcsm/a/xF33tqFH3s4MnxJDR35MwCL/?lang=pt\#. Acesso em 20 jul. 2020.

BRASIL. Lei ñ 4.024, de 20 de dezembro de 1961. Fixa as Diretrizes e Bases da Educação Nacional. Disponível em: https:/ /www2.camara.leg.br/legin/fed/lei/1960-1969/lei-4024-20-dezembro1961-353722-normaatualizada-pl.pdf. Acesso em: 20 jul. 2020.

BRASIL. Lei $n^{\circ}$ 5.692, de 11 de agosto de 1971. Fixa Diretrizes e Bases para o ensino de $1^{\circ}$ e $2^{\circ}$ graus, e dá outras providências. Disponível em: http://www.planalto.gov.br/ccivil_03/leis/15692.htm. Acesso em: 13 jul. 2020.

BRASIL. Constituição da República Federativa do Brasil de 1988. Disponível em: http://www.planalto.gov.br/ccivil_03/constituicao/constituicao.htm. Acesso em 14 jul. 2020.

BRASIL. Lei ñ 9.394, de 20 de dezembro de 1996. Estabelece as diretrizes e bases da educação nacional. Disponível em: http://www.planalto.gov.br/ccivil_03/leis/19394.htm. Acesso em: 13 jul. 2020.

BRASIL, Resolução CEB n 3, de 26 de junho de 1998. Institui as Diretrizes Curriculares Nacionais para o Ensino Médio.

BRASIL. Parâmetros Curriculares Nacionais: Ensino Médio. Brasília: MEC/SEF, 2000.

BRASIL. Lei n.11.769 de 18 de agosto de 2008. Altera a Lei no 9.394, de 20 de dezembro de 1996, Lei de Diretrizes e Bases da Educação, para dispor sobre a obrigatoriedade do ensino da música na educação básica. Disponível em: http:/ /www.planalto.gov.br/ccivil_03/_ato20072010/2008/lei/111769.htm. Acesso em: 13 jul. 2020.

BRASIL. Lei n. 12.287 de 13 de julho de 2010. Altera a Lei no 9.394, de 20 de dezembro de 1996, que estabelece as diretrizes e bases da educação nacional, no tocante ao ensino da arte.

Disponível em: http://www.planalto.gov.br/ccivil_03/_Ato2007-2010/2010/Lei/L12287.htm. Acesso em: 13jul. 2020.

BRASIL/MEC. Diretrizes Curriculares Nacionais Gerais da Educação Básica. Brasília: MEC, 2013. Disponível em:

http:/ / portal.mec.gov.br/index.php?option $=$ com_docman\&view $=$ download\&alias $=15547$ diretri zes-curiculares-nacionais-2013-pdf-1\&Itemid=30192. Acesso em: 13 jul. 2020.

BRASIL. Lei no 13.005, de 25 de junho de 2014. Aprova o Plano Nacional de Educação - PNE e dá outras providências. Disponível em: http://www.planalto.gov.br/ccivil_03/_ato20112014/2014/lei/113005.htm. Acesso em: 20 jul. 2020.

BRASIL. Lei n. 13.278 de 02 de maio de 2016. Altera o \6o do art. 26 da Lei no 9.394, de 20 de dezembro de 1996, que fixa as diretrizes e bases da educação nacional, referente ao ensino da 
arte. Disponível em: www.planalto.gov.br/ccivil_03/_Ato2015-2018/2016/Lei/L13278.htm. Acesso em: 13 jul. 2020.

BRASIL. Lei n. 13.415 de 16 de fevereiro de 2017. Altera a Lei no 9.394, de 20 de dezembro de 1996, que estabelece as diretrizes e bases da educação nacional, no tocante ao ensino da arte.

Disponível em: http://www.planalto.gov.br/ccivil_03/_ato2015-2018/2017/lei/113415.htm. Acesso em: 20 jul. 2020.

BRASIL. Base Nacional Comum Curricular. Brasília: MEC/Secretaria de Educação Básica, 2018. Disponível em:

http://basenacionalcomum.mec.gov.br/images/BNCC_EI_EF_110518_versaofinal_site.pdf. Acesso em 10 jan. 2020.

FERNANDEZ, A. A Inteligência Aprisionada. Tradução de Iara Rodrigues. Porto Alegre: Artmed: 1991.

FERREIRA, G. S. Educação do Corpo pela Dança na Escola Profissionalizante: contexto do Instituto Federal de Educação, [...]. 170 f. Tese (Mestrado em Dança) - Universidade Federal da Bahia. Salvador/BA, 2013.

JAKIMIU, V. C. Os embates em torno da consolidação da arte enquanto área de conhecimento no currículo escolar brasileiro In: EDUCERE XIII Congresso Nacional de Educação. Curitiba, 2017. Anais, 2017, p. 6717 - 6731. Disponível em:

http://educere.bruc.com.br/arquivo/pdf2017/23393_11695.pdf. Acesso em: 08 dez. 2018.

MARQUES, I. A. Dançando na Escola. São Paulo: Cortez, 2003.

MENEZES, A. H. N. et al. Metodologia cientifica: teoria e aplicação na educação a distância. Universidade Federal do Vale do São Francisco, Petrolina-PE, 2019. Disponível em: https://portais.univasf.edu.br/noticias/univasf-publica-livro-digital-sobre-metodologia-cientificavoltada-para-educacao-a-distancia/livro-de-metodologia-cientifica.pdf. Acesso em 30 jul. 2020.

ORTEGA, R. A implementação da BNCC deve avançar: Instabilidades não podem afetar base curricular. Folha de São Paulo, 14 ago. 2016. Disponível em:

https://www1.folha.uol.com.br/educacao/2016/08/1802639-base-curricular-evitatratar-arte-como-adorno-mas-conteudo-e-vago.shtml. Acesso em: 15 jul. 2019.

PERES, J. R. P. Questões atuais do ensino de Arte no Brasil: O lugar da Arte na Base Nacional Comum Curricular. Revista do Departamento de Desenho e Artes Visuais. Vol.1, No.1: Edição de Lançamento - Artigos e Relatos. 2017. Disponível em: https://www.cp2.g12.br/ojs/index.php/revistaddav/article/view/1163. Acesso em: 20 jun. 2020.

RODRIGUES, C. C. Sobre Tempos e Lugares no Currículo Escolar Brasileiro. Revista Espaço do Curriculo, v.6, n.1, p.69-80,janeiro a abril de 2013. Disponível em: http://periodicos.ufpb.br/ojs2/index.php/rec. Acesso em: 15 jun. 2020.

SILVA, P. C.; ALEXANDRE, A. C. de F. Dança: Imagem Corporal e a Descoberta de si Mesmo. Revista Brasileira de Educaşão e Cultura. n. IX, 2014. Disponível em:

http://periodicos.cesg.edu.br/index.php/educacaoecultura. Acesso em: 15 abr. 2019. 
SILVA, R. L. A dança no Ensino Médio Integrado: um estudo de caso no Instituto Federal de Educação, Ciência e Tecnologia do Maranhão. 137 f. Tese (Mestrado em Dança) - Universidade Federal da Bahia. Salvador/BA, 2017.

VASQUEZ, Ana L. E O Ensino de Arte no Brasil: A Arte como Ocupação.

Anais do VIII Fórum de Pesquisa Científica em Arte. Curitiba: ArtEmbap, 2011.

WOSIEN, B. Dança: um caminho para a totalidade. São Paulo: TRIOM, 2000. 